\title{
Teaching Helping Babies Breathe via Telehealth: A New Application in Rural Guatemala
}

\author{
Caitlin Jones-Bamman $^{a}$ Susan Niermeyer ${ }^{a, c}$ Kelly McConnell ${ }^{c}$ \\ John F. Thomas ${ }^{\mathrm{a}, \mathrm{b}}$ Christina Olson ${ }^{\mathrm{a}, \mathrm{b}}$ \\ a Department of Pediatrics, University of Colorado, Aurora, CO, USA; ${ }^{\text {b } T e l e h e a l t h ~}$ \\ Department, Children's Hospital Colorado, Aurora, CO, USA; ' $C e n t e r$ for Global Health, \\ Colorado School of Public Health, Aurora, CO, USA
}

\section{What Is It about?}

In this pilot study, the standard Helping Babies Breathe (HBB) course was taught using telehealth rather than in-person education. The course was successful in delivering course material, as all but one learner (94\%) passed the course. The course was also well received by learners, who felt it was comparable to in-person education. Finally, the telehealth model provided significant time and costsaving benefits. This model could be used to improve access to HBB globally.

\section{Keywords}

Neonatal resuscitation · Helping Babies Breathe $\cdot$ Telehealth $\cdot$ Global health · Education

\begin{abstract}
Background: Helping Babies Breathe (HBB) is a neonatal resuscitation curriculum that teaches life-saving interventions utilized in the first minutes after birth, reducing morbidity and mortality. Traditionally, it requires in-person facilitators for didactic and hands-on training. Objectives: The aim of this study was to offer HBB to nurses and nursing students in Guatemala, with the lead facilitator presenting concepts via telehealth and in-person facilitators providing hands-on demonstration. Methods: Learners completed pre- and post-tests that included the standard HBB knowledge check, as well as an assessment of the course teaching model. Learners also completed the standard Objective Structured Clinical Evaluations (OSCEs). Results: Eighteen learners were included in the analysis. All but one learner (94\%) passed the course, and the average percent improvement from the pre- to post-test was $12 \%$. All learners achieved passing scores on the OSCEs. Learners responded positively to questions regarding the technology, connection with the instructor, and ability to ask questions. Ninety-
\end{abstract}


four percent of the learners agreed with the statement "this lecture was as good via telehealth as in person." A cost analysis demonstrated approximately USD 3,979.00 in savings using telehealth compared to a standard in-person course. Conclusions: The telehealth model was successful in delivering course material to the learners and was well received. This model represents a cost-effective way to improve access to HBB. This study may not be generalizable to other populations, and the ability to use telehealth requires reliable internet connectivity, which may not be available in all settings. Further study and expansion of this pilot are needed to assess success in other settings.

\section{Introduction}

Neonatal mortality is a pressing issue in low- and middle-income countries (LMICs). Globally, approximately 637,000 neonatal deaths result from intrapartum-related hypoxic events [1], with an additional 2.6 million stillbirths annually [2]. In routine deliveries, 5-10\% of all newborns require stimulation to help them breathe, and approximately $3-6 \%$ of this group require further resuscitation [3]. Disparities in skilled resuscitation access remain prevalent in LMICs.

To improve birth outcomes, programs such as Helping Babies Breathe (HBB) have been implemented. HBB is a neonatal resuscitation curriculum that improves birth attendants' abilities to provide life-saving interventions after birth [4]. It has been used to train individuals in many languages [5], and traditionally utilizes in-person education.

Telehealth employs technology to deliver healthcare and education remotely to reduce health disparities and improve access to care [6,7]. Prior studies have compared in-person versus telehealth courses in neonatal resuscitation and found equivalent gain in knowledge and skills, as well as high participant satisfaction [8,9]. However, telehealth delivery of HBB to a rural setting in an LMIC has not been previously reported. Implementation and evaluation of a virtual HBB course would potentially allow for broader dissemination and lower costs, as travel expenses for master trainers comprise the largest expense in implementing a HBB course [10].

\section{Methods}

This project was a collaboration between the University of Colorado Center for Global Health (CGH), the Children's Hospital Colorado Telehealth Department, and the Center for Human Development (CHD) in Guatemala and received exempt status from the Colorado Multiple Institutional Review Board.

The CHD is a health center created through partnership between the CGH and a local agricultural company, AgroAmerica, in southwest Guatemala. It serves a population of 30,000 people where the primary language is Spanish. The CHD is staffed by local nurses, local doctors, and visiting US doctors, and includes a birth center for uncomplicated deliveries.

A telehealth-enabled HBB course taught in Spanish was provided to nurses and nursing students at the CHD free of charge before opening the birth center. Learners enrolled in the course received an identification number, which was used to collect data.

To connect, the distant instructor used institutional Wi-Fi and video conferencing equipment. Learners at the CHD used a Wi-Fi connection, laptop and projector, which were already available at the clinic for other uses without additional cost. Both ends connected through Children's Hospital of Colorado's existing software-based telemedicine platform. 
The lead facilitator was a HBB master trainer in the United States who demonstrated skills remotely using a NeoNatalie simulator, with the camera focused on the simulator and the facilitator's hands. Two in-person facilitators were also present to assist with on-site skill demonstration if necessary; they were resident physicians who had completed the Neonatal Resuscitation Program provider course and were on-site at the CHD. Each learner pair had a NeoNatalie simulator. The course was taught in the same time frame as traditional in-person HBB, roughly one half-day, and was offered twice. The lead facilitator was connected through the telemedicine platform throughout the entire course.

Learners were held to the same standards for passing as in-person classes and were evaluated with the HBB Knowledge Check, Bag-Mask Skill Check, and Objective Structured Clinical Evaluation (OSCEs) A/B. The skill checks were done with both the in-person facilitators and the master trainer monitoring via telehealth. Learners also completed a pre-test before the start of the course, and a satisfaction survey after the course. Survey questions were created by study authors to address the specifics of this telehealth model.

All testing and evaluations were done through Google Forms ${ }^{\circledR}$ (Google Docs, RRID: SCR_005886). The anonymous survey data were collected and stored in Google Docs and processed in Microsoft Excel ${ }^{\circledR}$.

\section{Results}

\section{Demographics}

Eighteen learners were included in the analysis with $39 \%$ being nursing students and the remainder being practicing nurses. Practicing nurses had differing experience, with 39\% having worked for $1-3$ years, $11 \%$ for $3-5$ years, and $11 \%$ for $>5$ years. Most learners (89\%) had attended between 1-10 deliveries prior to the course, with the remainder (11\%) having never attended a delivery. Information regarding any resuscitation performed or observed in previously attended deliveries was not available. Most learners had no previous experience with telehealth, but $27 \%$ reported using telehealth "many times," and $11 \%$ reported using telehealth "1-2 times."

\section{Knowledge Gain}

The mean score on the HBB Knowledge Check taken before the course was $81 \pm 12.5 \%$ (range 53-94). Successful course completion required a score of $\geq 80 \%$ on the post-test HBB Knowledge Check and demonstration of proper technique on the OSCEs. All but one learner $(94 \%)$ passed the course. The mean score on the post-test was $89 \pm 7 \%$ (range $71-100$ ). The mean improvement from the pre- to post-test was $12 \%$, with a range of -8 to $+56 \%$. All learners demonstrated proper technique on the OSCEs.

\section{Learner Evaluation}

Learners responded to statements regarding the course using a 4-point Likert scale $1=$ strongly disagree, 2 = disagree, 3 = agree, and 4 = strongly agree). Overall responses were positive; however, one learner responded negatively to every question (score of 1). No written feedback was provided, so is unknown if this individual was dissatisfied or misinterpreted the scale. This learner was included in the analysis.

Technology statements asked about the ability to see and hear the instructor, ease of use, and perceived connection to the instructor. Ninety-four percent $(17 / 18)$ responded positively. With regards to the telehealth model, $94 \%$ of the learners agreed with the statement "this lecture was as good via telehealth as in person," but interestingly, $50 \%$ of the learners $(9 / 18)$ agreed that "this course would be better carried out in-person only." Ninety-four 
Table 1. Learner evaluation of the course

\begin{tabular}{llll}
\hline Statement & $\begin{array}{l}\text { Mean } \\
\text { Likert } \\
\text { Score }\end{array}$ & SD & $\begin{array}{l}\text { Number of "Agree" } \\
\text { responses (Likert } \\
\text { score 3 or 4) }\end{array}$ \\
& & & \\
\hline Technology & 3.72 & 0.75 & $17(94 \%)$ \\
$\quad$ I could hear the instructor well & 3.72 & 0.75 & $17(94 \%)$ \\
$\quad$ I could see the instructor well & 3.72 & 0.75 & $17(94 \%)$ \\
$\quad$ This system is easy to use & & & \\
Connection to instructor & 3.50 & 0.79 & $17(94 \%)$ \\
$\quad$ I felt connected to the instructor & 3.78 & 0.73 & $17(94 \%)$ \\
$\quad$ I believe the instructor cared about my learning & 3.6 & 0.76 & $17(94 \%)$ \\
$\quad$ I was able to ask the instructor my questions & 3.72 & 0.75 & $17(94 \%)$ \\
$\quad$ The instructors listened to my questions & & & \\
Telehealth model & 3.83 & 0.71 & $17(94 \%)$ \\
$\quad$ This mode of teaching maintained my interest & 3.44 & 0.86 & $16(89 \%)$ \\
$\quad$ This lecture was as good via telehealth as in person & 2.5 & 0.86 & $9(50 \%)$ \\
$\quad$ This course would be better carried out in person only & & & \\
Course content & 3.83 & 0.71 & $17(94 \%)$ \\
$\quad$ This course improved my knowledge on this topic & 3.72 & 0.73 & $17(94 \%)$ \\
$\quad$ This course improved my skills in this topic & 3.6 & 0.77 & $17(94 \%)$ \\
$\quad$ Overall, I can help babies breathe & & & \\
\hline
\end{tabular}

Table 2. Cost estimate analysis

\begin{tabular}{lll}
\hline & Daily rate & Total \\
\hline Flight & - & USD 900.00 \\
Transportation & - & USD 46.00 \\
Hotel & USD 95.00 & USD 190.00 \\
Room and board at CHD & USD 25.00 & USD 50.00 \\
Travel per diem & USD 96.00 & USD 384.00 \\
Daily salary compensation & USD 600.00 & USD 3,000.00 \\
\hline Grand total & & USD 4,570.00 \\
\hline
\end{tabular}

percent of the learners responded positively to statements about the ability of the course to improve their knowledge and skills overall (Table 1).

\section{Cost Evaluation}

The only cost for the telehealth course was the master trainer's time (two half-day sessions, or 1 day total). At our institution, the average faculty physician earns USD $165,000 /$ year, corresponding to about USD 600/day. As equipment and internet access were already available, the total faculty cost of the telehealth course was estimated to be USD 600.00 .

The estimated cost for an in-person equivalent course was USD 4,570.00 (Table 2). This estimate is based on a 5-day trip to and from the CHD, with 1 of these days as a working day - the rest are needed for travel given the remote location. The estimate includes compensation for: airfare, transportation, accommodation, per diem costs, and salary compensation. Thus, the telehealth model saved approximately USD 3,979.00 when compared to in-person instruction. 


\section{Discussion and Conclusion}

Overall, using telehealth to deliver HBB was successful and cost-effective. Learners mastered the material, as demonstrated by a $94 \%$ passing rate and score improvement between pre- and post-testing. There is no published data on passing rates to reference, but anecdotal evidence from experienced master trainers at our institution indicates the passing rate for this pilot met or exceeded the passing rate from their in-person courses. Learners also mastered hands-on skills as demonstrated during the standardized OSCEs.

Learners liked the telehealth model and did not report significant technical difficulties. Learners felt connected to the instructor and thought the course was comparable to in-person training, although 50\% expressed a preference for in-person training had it been equally available. At the end of the course, learners felt confident in the skills they learned.

The telehealth model was not only demonstratively less expensive to deliver than a comparable in-person course, but also eliminated the need for travel, allowing for more frequent and less expensive trainings. Given the cost and time savings, the telehealth model has the potential to broaden the reach of this training, making it more accessible to geographically isolated communities and communities that otherwise could not afford or access a master trainer, but do have access to clinicians who can facilitate skill demonstration.

There are several limitations to this pilot project. Our learners were nurses and nursing students, many of whom had attended births prior to the course and had baseline medical knowledge, which could have affected the passing rate. However, HBB is typically taught to learners with delivery experience. Some learners in our course also had previous telehealth experience, so it is possible that individuals with no telehealth experience would have a harder time learning through this model. Lastly, many of the learners knew the master trainer from other work, which may have influenced their responses to questions about their comfort with the instructor.

Our cost comparison did not consider the cost of pre-existing telehealth infrastructure, which is highly variable depending on existing in-country and site-specific infrastructure. This could be a barrier to those looking to implement a similar program in an area without access to basic video-conferencing technology. The cost comparison was also based on compensation and travel expenses for a US-based master trainer, and costs would be lower for a master trainer already in the country, if available. The cost comparison also did not include pay for the on-site facilitators.

Further study and expansion of this pilot are needed to assess success in other settings, but it demonstrates significant promise for teaching evidence-based neonatal resuscitation skills to healthcare personnel in LMIC's with access to the internet. This model also has the potential to be a cost-effective way to provide ongoing skill retention and skill enhancement training as well as expand the reach of the HBB program.

\section{Acknowledgements}

We thank the in-person facilitators, Sarah Isbey and Robin Ortenberg, for their contribution to this project.

\section{Statement of Ethics}

The authors have no ethical conflicts to disclose. Formal written informed consent was not obtained from course participants as this pilot project was reviewed and received exempt status from the Colorado Multiple Institutional Review Board. 


\section{Disclosure Statement}

The authors have no conflicts of interest to declare.

\section{Funding Sources}

The authors have no funding sources to disclose.

\section{Author Contributions}

K.M. and C.O. conceived of the original study. K.M., C.O., S.N., and J.F.T developed the telehealth course design. K.M., C.O., J.F.T., and C.J.-B. helped with course organization, overall execution of the course, and data collection. K.M. was the master trainer responsible for teaching the course with direct observation by C.O. C.J.-B. wrote the first draft of the manuscript and incorporated input from all authors. All authors approved the final manuscript.

\section{References}

1 Liu L, Oza S, Hogan D, Chu Y, Perin J, Zhu J, et al. Global, regional, and national causes of under-5 mortality in 2000-15: an updated systematic analysis with implications for the Sustainable Development Goals. Lancet. 2016 Dec;388(10063):3027-35.

2 Blencowe H, Cousens S, Jassir FB, Say L, Chou D, Mathers C, et al.; Lancet Stillbirth Epidemiology Investigator Group. National, regional, and worldwide estimates of stillbirth rates in 2015, with trends from 2000: a systematic analysis. Lancet Glob Health. 2016 Feb;4(2):e98-108.

3 Lee AC, Cousens S, Wall SN, Niermeyer S, Darmstadt GL, Carlo WA, et al. Neonatal resuscitation and immediate newborn assessment and stimulation for the prevention of neonatal deaths: a systematic review, metaanalysis and Delphi estimation of mortality effect. BMC Public Health. 2011 Apr;11 Suppl 3:S12.

4 Singhal N, Lockyer J, Fidler H, Keenan W, Little G, Bucher S, et al. Helping Babies Breathe: global neonatal resuscitation program development and formative educational evaluation. Resuscitation. 2012 Jan;83(1):90-6.

5 Seto TL, Tabangin ME, Josyula S, Taylor KK, Vasquez JC, Kamath-Rayne BD. Educational outcomes of Helping Babies Breathe training at a community hospital in Honduras. Perspect Med Educ. 2015 0ct;4(5):225-32.

6 Tomlinson J, Shaw T, Munro A, Johnson R, Madden DL, Phillips R, et al. How does tele-learning compare with other forms of education delivery? A systematic review of tele-learning educational outcomes for health professionals. N S W Public Health Bull. 2013 Nov;24(2):70-5.

7 Flodgren G, Rachas A, Farmer AJ, Inzitari M, Shepperd S. Interactive telemedicine: effects on professional practice and health care outcomes. Cochrane Database Syst Rev. 2015 Sep;(9):CD002098.

8 Loewen L, Seshia MM, Fraser Askin D, Cronin C, Roberts S. Effective delivery of neonatal stabilization education using videoconferencing in Manitoba. J Telemed Telecare. 2003;9(6):334-8.

9 Jain A, Agarwal R, Chawla D, Paul V, Deorari A. Tele-education vs classroom training of neonatal resuscitation: a randomized trial. J Perinatol. 2010 Dec;30(12):773-9.

10 Vossius C, Lotto E, Lyanga S, Mduma E, Msemo G, Perlman J, et al. Cost-effectiveness of the "helping babies breathe" program in a missionary hospital in rural Tanzania. PLoS One. 2014 Jul;9(7):e102080. 